\title{
Methodological Prerequisites for the Formation of a Favorable Investment Climate in Mining Regions in Terms of their Implementation of the Concept of Sustainable Development
}

\author{
Gennady Alexandrov ${ }^{1}$, and Aleksandr Iablonev ${ }^{1, *}$ \\ ${ }^{1}$ Tver State Technical University (TvSTU), 170026, Afanasy Nikitin emb., 22, Tver, Russia
}

\begin{abstract}
The purpose of this study involves the development of new methodological approaches to solving the urgent problem of implementing the concept of sustainable development in the country, its regions, industries and enterprises. It is clear, that the specifics of the mining activity predetermines both the special nature of interests, contradictions and industrial relations, developing in this area, and the adequacy of the approach to setting and solving the tasks of achieving sustainable development goals (SDGs). They consist, firstly, in determining the influence of investment processes on the formation of a balanced system of sustainable development of the region, in which financial and economic goals would be harmonized with environmental and social processes, and, secondly, in developing a methodology and a specific method of diagnostics and assessment systems of factors, that manifest themselves as barriers and restrictions, threats and challenges. At the end, the obtained results of the study should contribute to significant progress in solving the problem of attracting investments and implementing the concept of sustainable development of mining regions.
\end{abstract}

\section{Introduction}

In this article, in the order of formulation, the problems are considered, the relevance and novelty of which are due to the implementation of the concept of sustainable development in Russia. The subject area of their research is the development of both theoretical approaches to the implementation of the Sustainable Development Goals (SDGs) and adequate interim measures to create an environment in mining regions, favorable to attract sustainable investment. As you know, the concept of sustainable development was formulated and adopted for implementation relatively recently. The very term "sustainable development" was introduced by the World Commission on Environment and Development (WCED) [1] in 1987 in "Our Common Future" Report, as a process of harmonious, balanced development economic and social processes. Its implementation aims to ensure, that natural resources, investment, scientific and technological advances, personal

\footnotetext{
*Corresponding author: alvovich@mail.ru
} 
development and institutional change are aligned with each other and strengthen current and future capacities to meet human needs and aspirations. Subsequently, the UN Conference on Environment and Development (Rio de Janeiro, 1992) adopted a program document on the implementation of the concept of sustainable development [2].

As for the Russian Federation, the Concept of the Transition to Sustainable Development was adopted in 1996 (Presidential Decree No. 440 of 01.04.1996). In this article, we are not able to consider this concept in detail. However, we note that its origin is connected, as indicated in a number of publications [3,4], with the fact, that further development of the economy is impossible without taking into account the impact on it of social, economic, environmental problems and the risks of various kinds of conflicts, which also cause social fears, that undermine the well-being of the population [5]. In addition, the presence of determinants of social fears has a direct impact on investor sentiment and their motivation to invest [6].

Moreover, as noted in the aggregated BDO International Business Compass [7], economic growth is not the best mechanism for improving people's lives. Therefore, as noted in the WCED Report, too much emphasis on economic growth in relatively welldeveloped countries suggests a typical business approach, accompanied by only small adjustments to reduce the impact of industries on the environment. However, growth and development are not the same thing: growth means more, and development means better. Therefore, the time has come to destroy the "past patterns" [1]. At the same time, the implementation of the concept of sustainable development from the very beginning, and even now, as noted in a number of publications, encounters various kinds of difficulties, both theoretical and practical (see, for example, $[8,9]$ ). They are primarily due to the need for a balanced implementation of economic, social and environmental practices, taking into account a large number of different indicators, the presence of various kinds of restrictions and contradictions (which are discussed below). On the investment side of sustainable development, as noted in the World Investment Report 2020, foreign investment has grown sluggishly over the past decade.

At the same time, it is predicted, that in the future, the inflow of investments to countries, including ours with its mining regions, which are mainly export-oriented in raw materials production, will be significantly affected [10]. And, according to some analysts, the weakening of dependence on the export of raw materials contributes to an increase in the role of foreign direct investment in ensuring the dynamics of economic growth [11]. It is also noted that the achieved level of economic development of the country, its specific regions and their ability to withstand various kinds of crises occupies not the last place among the factors influencing economic growth and attraction of investments [12]. However, an analysis of 128 national investment profiles shows that so far, only a few cases have a specific roadmap to encourage investment in the SDGs. In addition, the existing investment promotion instruments applicable to the SDGs are very limited in number and do not take a systematic approach. Moreover, in general, less than half of the UN member states have specific instruments to promote investment in the SDGs, and, on average, each of them provides for regulatory measures in no more than three sectors or areas of action related to the SDGs. In many other countries, there are no such measures at all and, in general, the investment policy, that ensures the achievement of the SDGs, is not being implemented quickly enough [10].

At this point, attention should be paid to the fact, that foreign publications are quite actively discussing an assumption, that behind the cover of the concept of sustainable development there are intentions to implement plans for international domination of economically developed countries to institutionalize market inequality or restore traditional hierarchies of power reminiscent of the colonial era [13]. Or that it is a comprehensive UN plan to create an authoritarian world government through international rules and treaties 
under the guise of environmental protection and social justice (see, for example "What is AGENDA 21?" [1] Of course, the analysis of this kind of views on the concept of sustainable development requires a separate study.

\section{Method Used}

The situation with the implementation of the concept of sustainable development in relation to the mining region presupposes attracting investments for the SDGs. However, the solution to this problem depends on how attractive the region itself is for investment. Hence, the most important tasks are, firstly, the creation in the regions of an adequate environment for attracting sustainable investments, and, secondly, the identification and elimination of various kinds of barriers and restrictions, threats and challenges, that negatively affect the investment attractiveness of the mining business operating in the region.

At the same time, it is in connection with the attraction of investments for the SDGs that an objective contradiction arises in relations between the region with its need to ensure sustainable development and the economic interests of investors. Specifically, it is due to the fact that the focus of investments on achieving, in addition to economic goals, of an environmental and social nature, causes, as a rule, additional costs, that limit economic activities and increase investment risks [8].

Thus, the economic interests of producers are affected, and along with other factors, that determine the investment attractiveness of specific investment objects, they negatively affect the motivation to invest. In this regard, as noted in the WCED Report, the resolution of this contradiction is possible only on the basis of making mutually beneficial decisions [1]. In order to identify contradictions and factors, that negatively affect the investment attractiveness in general and the mining activity, in particular, a new method based on a systematic approach is proposed for use, the essence of which is the integration of two independent subsystems into an integral system ("levels-factors").

The first of them is a structured tiered system (enterprise-industry-region-national economy), in which at each of these structural levels its own characteristic environment (investment climate) is formed.

The second is a system of factors that characterize the environment, that has developed at each of these structural levels. Note, that in the current practice of assessing the investment climate, a predominantly factorial approach prevails. In this case, the factors are considered mainly in the form of a simple (summative) system, regardless of which of the hierarchical levels and how they manifest themselves. The initial level of the first system is the enterprise, in which the production process is actually carried out, and which is the primary link in the national economic system. Any primary link, in addition to the general that characterizes it, carries out a special type of activity, its investment attractiveness, is due to its belonging to a specific industry, a component of which is the enterprise. Thus, the specifics of the industry determines a special type and role of factors, that form the attractiveness of investment objects.

At the same time, the formation of the environment in which investment processes are carried out takes place in the regions where enterprises are created, operate and develop. It is clear, that the regions differ significantly in their sectoral orientation, resource opportunities, social and environmental priorities in the development of territories. In other words, the implementation of the sustainable development strategy largely depends on the investment attractiveness of the regions themselves, on those factors, that form the conditions, that facilitate or impede the inflow of investments. But, of course, the investment climate, that is developing at the lower levels of the economic hierarchy, is largely influenced by factors, that are formed at the level of the national economy. 
Here it is important to understand what are the factors, that have developed at the federal level, and what is their negative impact on the formation of the investment climate at the regional level and on the attractiveness of enterprises, taking into account their industry affiliation. And before answering this question, let us dwell on the principles of formation in the system of "levels-factors" of the second subsystem - "factors", more precisely, of their structured groupings. When forming groupings, we proceed from the provisions of economic theory, that the production process is the unity of its two components: productive forces (means of labor and production conditions) and production relations. And since, as shown above, the essence of the production process is revealed in economic, administrative-legal, resource-technical, as well as social and environmental aspects, it would be logical to form, respectively, and determining the investment attractiveness of four groups of factors: economic, resource-technical, administrative-legal and socio-environmental.

However, it should be taken into account, that the production process in the mining industry differs significantly from other spheres and sectors of the national economy in that the mining industry is distinguished by the presence of such a factor of production as subsoil. This, in turn, affects the special nature of production relations, the most important component of which is rent relations. The latter, as you know, are implemented in certain organizational and economic forms (adequate to objective economic relations) and are regulated by administrative and legal institutions and mechanisms. Thus, the matter remains to identify and evaluate specific factors, representing the relevant species groups and manifested as barriers, restrictions, threats and challenges, which, when implementing the concept of sustainable development, conflict with the interests of investors and negatively affect the attraction of sustainable investments. They are formed both at the level of the enterprises themselves and on the "upper floors" of the economic hierarchy and characterize, among other things, the situation with the investment climate in the mining region.

Before turning to the results of using our proposed original methodological approach to diagnosing and assessing the investment climate at the level of a mining region in the next section of this publication, we note that the "levels-factors" system may well be represented in a matrix form. Thus, it is possible to obtain sixteen combinations of appropriate combinations (four levels into four groups of factors) and determine their content.

\section{Results and discussion}

The result of using the proposed methodological approach should be the positioning of the mining region in the "levels-factors" system. As shown above, the sustainable development of the mining region is largely due to the investment attractiveness of the regional environment and, accordingly, the mining activity itself. And, since we are talking about the implementation of the concept of sustainable development, the factors, that make up the socio-ecological group are becoming increasingly important in assessing investment attractiveness.

This is explained by the fact that, on the one hand, the implementation of the sustainable development goals depends on them. On the other hand, they, in conflict with the achievement of financial and economic goals, manifest themselves as barriers and restrictions, that negatively affect the motivation to attract sustainable investments. The need to resolve this contradiction makes it necessary to analyze the factors of the administrative-legal group, that characterize the system of superstructure organizationeconomic relations, the formation of which, including at the regional level, is aimed at resolving the contradictions between socio-ecological and economic practices. Along with the traditionally considered factors inherent in any type of activity and characterizing the 
situation with the investment climate in any territorial formations, in the mining region, they acquire a specific form and content due to the characteristics of a particular mining industry [14].

Common key factors of the socio-ecological group are: demography; migration; social infrastructure; social status of the population; the level of social tension, anxiety and conflict; the state of affairs with ecology and environmental protection. In particular, for mining enterprises and regions, social and environmental factors considered in the aspect of achieving the SDGs are closely interrelated, since the mining industry itself is a source of negative impact on nature. For example, the deterioration of the ecological situation leads to the emergence of a number of social problems, that negatively affect the living conditions of the population. At the same time, the investor is in a position, in which, in accordance with the SDGs, obligations are imposed on him for social security not only for workers in extractive industries, but also for the formation of mechanisms to protect the population of the region.

However, the fulfillment of these obligations, especially for the development of social infrastructure, increasing social well-being, the implementation of environmental measures to protect the environment from all kinds of pollution, depletion of non-renewable resources and energy, etc. requires additional costs from him. But more often than not, they do not bring any significant economic results. On the contrary, these costs turn into damage, which manifests itself as risks, that negatively affect the motivation to invest. As a result, the problem arises of determining adequate measures to ensure their reduction and, thereby, contribute to the achievement of the SDGs. It is clear, that the solution to this problem is due to the presence of a number of factors of the administrative- legal group, that characterize the situation with the investment climate in the region. The main thing is how they contribute to resolving contradictions, related to the implementation of the SDGs.

These are: the socio-political situation in the region; the nature of the relationship between business and government, the population of the region and business; compliance with the rule of law and legal order in the region; the adequacy of regional legislation and the willingness of the authorities to reform it; the effectiveness of tax administration, the possibilities and intentions of the regional authorities to improve it; the nature of the participation of the regional authorities in accompanying investments, aimed at the implementation of the SDGs; the presence of corruption and criminal phenomena, bureaucratic problems in the region; the degree of transparency in the actions of regional authorities; their attitude to corporate conflicts, counteraction to raider takeovers, hostile mergers and acquisitions. A number of problems associated with the involvement of administrative and legal factors may well be solved by the regions themselves by reforming the system of administration and regulation of organizational and economic relations. However, the state, represented by the federal authorities, has great opportunities in implementing institutional measures to establish the "rules of the game".

\section{Conclusion}

In conclusion, it is necessary to conclude, that the study was carried out in accordance with the set goal, and as a result, a solution to the problem of methodological support for the implementation of the concept of sustainable development of mining regions was proposed. At the same time, which is especially important in practical terms, it is implemented in the systematic approach "levels-factors" developed by the authors. As a result, it is possible to formulate a number of conclusions about the usefulness of specific research results. In our opinion, they will allow: firstly, to make significant progress both in theoretical and practical terms in solving the problem of the implementation of the concept of sustainable development by mining regions, taking into account everything, that is common, that 
characterizes regions in general, and mining regions, in particular; secondly, to identify, as a matter of priority, those factors, that most negatively affect the investment attractiveness of the region and, as a consequence, specific mining enterprises, to determine to what extent the presence of barrier and restrictive factors, threats and challenges, negatively affects the investment attractiveness of mining businesses and the regions concerned, and to what extent the factors behind the need to make sustainable investments in the SDGs conflict with the latter; and, finally, thirdly, to determine those specific measures of a superstructural (organizational and economic nature), that need to be developed and implemented at the appropriate levels of the economic hierarchy and, above all, at the regional level, in order to ensure the resolution of these contradictions implemented in the framework of economic policy. Thus, it will be possible to achieve mutually beneficial solutions in the implementation of investment activities and contribute to the growth of the social and natural environment, instead of constantly subjecting it to degradation. In addition, as a feedback, the implementation of sustainable development goals will have a positive effect on the image of mining regions, that is, on increasing their attractiveness for investors.

\section{Acknowledgement}

The reported study was funded by RFBR, project number 20-010-00124: "Improving the concept of economic security and assessing the level of its security in the aspect of investment attractiveness of enterprises".

\section{References}

1. World Commission on Environment and Development, Our Common Future (Oxford University Press, Oxford, 1987)

2. R. Smardon, Management of Environmental Quality, 19(1), 118-137 (2008)

3. B. Candelon, A. Carare, J-B. Hasse, J. Lu, Int. Econ., 161, 139-158 (2020)

4. N. Phuc Canh, N. Thanh Binh, S. Dinh Thanh, C. Schinckus, Int. Econ., 161, 159-172 (2020)

5. P. H. Leal, A. C. Marques, Int. Econ., 164, 36-47 (2020)

6. B. Grace Li, P. Gupta, J. Yu, Int. Econ., 151, 7-25 (2017)

7. B. Czarnecka, B. Schivinski, J. of Global Marketing, 0(4), 219-238 (2019)

8. R. Costanza, C. Folke, Ecological Economics and Sustainable Development (Manila, Philippines, 1994)

9. F. Biermann, Environment, 42(9), 22-31 (2020)

10. World Investment Report 2020, International Production Beyond the Pandemic (UN Publications, New York, 2020)

11. N. Stern, J. of Econ. Literature, 51(3), 838-859, (2013)

12. Z. Umar, D. Kenourgios, S. Papathanasiou, Econ. Model., 93, 112-124 (2020)

13. D. Chandler, Int. J. of Security and Development, 4(1), 1-14 (2015)

14. G. Alexandrov, A. Iablonev, E3S Web of Conf., 174, 04013 (2020) 